\title{
Review \\ Lipid peroxidation, oxidative stress genes and dietary factors in breast cancer protection: a hypothesis
}

\author{
Manuela Gago-Dominguez, Xuejuan Jiang and J Esteban Castelao
}

\begin{abstract}
USC/Norris Comprehensive Cancer Center, Department of Preventive Medicine, Keck School of Medicine of the University of Southern California, Los Angeles, California 90033-0800, USA
\end{abstract}

Corresponding author: M Gago-Dominguez, mgago@usc.edu

Published: 10 January 2007

This article is online at http://breast-cancer-research.com/content/9/1/201

(c) 2007 BioMed Central Ltd

Breast Cancer Research 2007, 9:201 (doi:10.1186/bcr1628)

\begin{abstract}
We have recently proposed that lipid peroxidation may be a common mechanistic pathway by which obesity and hypertension lead to increased renal cell cancer risk. During this exercise, we noted a risk factor swap between breast and kidney cancer (oophorectomy and increased parity, detrimental for kidney, beneficial for breast; high blood pressure, detrimental for kidney, beneficial for breast when it occurs during pregnancy; alcohol, beneficial for kidney, detrimental for breast, and so on). We have subsequently proposed the hypothesis that lipid peroxidation represents a protective mechanism in breast cancer, and reviewed the evidence of the role of lipid peroxidation on established hormonal and non-hormonal factors for breast cancer. Here, we review the evidence in support of lipid peroxidation playing a role in the relationships between dietary factors and breast cancer. Available evidence implicates increased lipid peroxidation products in the anti-carcinogenic effect of suspected protective factors for breast cancer, including soy, marine n-3 fatty acids, green tea, isothiocyanates, and vitamin D and calcium. We also review the epidemiological evidence supporting a modifying effect of oxidative stress genes in dietary factor-breast cancer relationships.
\end{abstract}

\section{Introduction}

Lipid peroxidation is a natural metabolic process under normal conditions. It can be divided into three stages: initiation, propagation and termination [1]. The initiation phase includes activation of oxygen and is rate limiting. Polyunsaturated fatty acids (the main component of membrane lipids) are susceptible to peroxidation. Lipid peroxidation is one of the most investigated consequences of reactive oxygen species' (ROS) actions on membrane structure and function. The idea of lipid peroxidation as a solely destructive process has changed during the past decade. It has been shown that lipid hydroperoxides and oxygenated products of lipid peroxidation degradation as well as lipid peroxidation initiators (that is, ROS) can participate in the signal transduction cascade
$[2,3]$, the control of cell proliferation, and the induction of differentiation, maturation, and apoptosis [4-6]. It has been shown that lipid peroxidation and ROS are triggers and essential mediators of apoptosis, which eliminates precancerous and cancerous, virus-infected and otherwise damaged cells that threaten our health [7-10]. In addition, although the essential n- 6 fatty acid linoleic acid has been shown to increase breast cancer in experimental studies, other n-6 fatty acids (such as conjugated linoleic acid, and gamma linolenic acid) and n-3 fatty acids (such as eicosapentaenoic acid, docosahexaenoic acid (DHA), and alpha-linolenic acid) have been shown to inhibit the growth of breast cancer in vivo and in vitro and this inhibition is correlated with the extent of lipid peroxidation generated in tumor cells [11]. This suppression of cancer growth is enhanced by pro-oxidants and eliminated by antioxidants, and this elimination is proportional to the inhibition of lipid peroxidation products by antioxidants [11].

We have recently proposed the hypothesis that lipid peroxidation represents a protective mechanism in breast cancer, and reviewed the evidence of the role of this process on established reproductive, hormonal, and non-hormonal factors for breast cancer [11]. There is some supporting evidence that lipid peroxidation may play a role in the potential anticarcinogenic effects of other breast cancer factors, including soy [12-18], marine n-3 fatty acids [19], isothiocyanates (ITCs) [20-23], green tea [24-28], and vitamin D [29] and calcium [30,31]. Here, we review the evidence in favor of lipid peroxidation playing a role in these relationships between dietary factors and breast cancer. We also review the evidence favoring a modifying effect of oxidative stress genes in these dietary factor-cancer associations.

$\mathrm{ALA}=$ alpha linolenic acid; CCND1 = cyclin D1; Cl = confidence interval; COMT = catechol-O-methyl transferase; DHA = docosahexaenoic acid; EGCG = epigallocatechin gallate; GST = glutathione $S$-transferase; ITC = isothiocyanate; MDA = malondialdehyde; MnSOD = manganese superoxide dismutase; $\mathrm{ROS}=$ reactive oxygen species. 


\section{Lipid peroxidation: beneficial, detrimental or both?}

There is ample evidence supporting a causative role of lipid peroxidation in selected human cancers, including kidney, liver and skin, and in degenerative diseases. In experimental models, estrogen treatment induces lipid peroxidation and subsequently increases the incidence of renal cell cancer [32,33]. Because estrogen is a risk factor for breast cancer, it has been hypothesized, based on this model, that lipid peroxidation may be one mechanism by which estrogen increases breast cancer risk [11]. But estrogen induces renal cancer or liver cancer in this experimental model, not breast cancer. Indeed, lipid peroxidation may be a relevant mechanism for renal carcinogenesis, a concept that we have proposed and that is strongly supported by experimental and epidemiological data [32-34], but there is a lack of experimental models in support of estrogens increasing lipid peroxidation and subsequently inducing breast cancer development [11]. In contrast, there is evidence favoring lipid peroxidation as an anticarcinogenic mechanism in breast cancer. A consideration of the literature on animal and in vitro studies suggests that an influence on breast cancer protection relates to the generation of lipid peroxidation products [11].

We believe that the beneficial or detrimental effects of lipid peroxidation on cellular structures may depend on several factors [11], such as baseline levels of ROS (inducers of lipid peroxidation), and the type of tissue, that is, slowly versus rapidly proliferating tissue, in which ROS exert their action [11], as we have discussed in detail in our prior communication [11].

\section{Role of lipid peroxidation on the relationships between dietary factors and breast cancer}

In general, the associations between dietary factors and breast cancer remain controversial in the epidemiological literature, but there is some support for a lipid peroxidation pathway and a protective effect from in vitro studies [11]. It is possible that the lack of consideration of the lipid peroxidation pathway and the implied modifying effects of related gene polymorphisms may account for some of the lack of consistency in previous epidemiological studies. We believe that many dietary factors have both antioxidant and pro-oxidant properties, but what is important is which property is responsible for their anti-cancer effect. We raise the possibility that a deficiency in lipid peroxidation, not an increased antioxidant potential, may be detrimental for breast cancer. This does not imply that antioxidants are detrimental for breast cancer, as different antioxidants may inhibit different cell structures with different affinity and intensity, such as lipids, proteins or other cell constituents. Thus, the lipid peroxidation theory does not contradict the fact that, in studies investigating blood levels of antioxidants and breast cancer risk, for example, the evidence of a benefit for protection is not clear but neither is evidence of harm.
In the following sections we consider the dietary factors n-3 fatty acids, n- 6 fatty acids, soy, ITCs, tea, and vitamin D and calcium in light of the lipid peroxidation mechanism.

\section{Marine n-3 fatty acids}

Eight cohort studies, conducted in Norway [35], Japan [36], Europe [37], the US [38-41], and Singapore [42], have examined fish or marine $\mathrm{n}-3$ fatty acids intake in relation to breast cancer; only one of them, the study from Singapore, found an association [42].

Results from case-control studies of marine n-3 fatty acids (eicosapentaenoic acid and DHA) measured in adipose tissue are mixed [43-47]. Maillard and colleagues [45] found strong inverse associations for $\mathrm{DHA}$, and for the marine $\mathrm{n}$ 3/total n- 6 fatty acids ratio. In a case-control study conducted in Finland, DHA level in breast adipose tissue, along with its dietary intake, were significantly lower in breast cancer patients compared to control patients, suggesting a protective effect of DHA in the risk of breast cancer [43]. Also, a case-control study conducted across five European countries found a decreased risk of breast cancer with an elevated ratio of marine $n-3$ fatty acids to total $n-6$ fatty acids in four of five centers [44]. In contrast to these findings, two case-control studies conducted in the US found no consistent association between $n-3$ fatty acid levels in adipose tissue and breast cancer risk $[46,47]$.

The reason for the discrepancy between the US and European studies remains unresolved. One hypothesis is these discrepancies may be due to differences in ranges of fish intake across the various populations [42]. Another hypothesis is that the inconsistencies may be due in part to interactions between $n-3$ fatty acids and antioxidant compounds in the diet, affecting their roles in breast cancer risk $[45,48,49]$. As pointed out above, data from experimental studies suggest that the strength of the association with marine $n-3$ fatty acids may be reduced in the presence of high antioxidant intake because the latter inhibit the formation of lipid peroxidation products, which have been proposed as the proximal anti-carcinogens $[48,50]$. In fact, several experimental studies showed that the suppression in cancer growth with n3 fatty acids is enhanced by pro-oxidants [51] and eliminated by antioxidants such as vitamin $E[11,18,51,52]$. This suggests that the anti-cancer effect of $n-3$ fatty acids is mediated, at least in part, by lipid peroxidation products and emphasizes the importance of the potential interactions of anti- and pro-oxidant compounds with marine n-3 fatty acids [45]. Maillard and colleagues [45] suggested that the lack of an association between marine n-3 fatty acids and breast cancer risk in US studies $[39,46,47,53]$ may be due, in part, to the interfering role of antioxidant vitamins, which are commonly taken as supplements in the US $[45,54]$.

As mentioned above, we recently published the first set of prospective results linking intake of marine $n-3$ fatty acids to 
breast cancer protection in Singapore Chinese women [42]. In our study, relative to the lowest quartile of marine n-3 fatty acid intake, individuals in the higher 3 quartiles exhibited a $26 \%$ reduction in risk of breast cancer (relative risk $=0.74$, $95 \%$ confidence interval $(\mathrm{Cl})=0.58,0.94)$. We also have published the first set of results in humans implicating the peroxidation products of marine $\mathrm{n}-3$ fatty acids as the proximal anticarcinogens [19], a notion strongly supported by experimental evidence [18,49,50,52,55-57]. Glutathioneassociated metabolism is a major mechanism for cellular protection against agents that generate oxidative stress, acting by eliminating products of lipid peroxidation [58,59]. Therefore, we hypothesized that individuals possessing the low activity genotypes of GSTM1, GSTT1 and/or GSTP1 (that is, GSTM1-null, GSTT1-null and GSTP1 AB/BB genotypes, respectively) $[60,61]$ may exhibit a stronger inverse association between marine $\mathrm{n}-3$ fatty acids and breast cancer than their high activity counterparts. This hypothesis was supported by study results [19].

\section{N-6 fatty acids}

Meta-analysis of case-control and prospective cohort studies on breast cancer have failed to demonstrate a convincing link between n-6 fatty acids and breast cancer development [6264]. In contrast, diets containing $n-6$ fatty acids have been shown to induce breast cancer in experimental studies [65]. N-6 fatty acids act as competitive inhibitors of n-3 fatty acids in fat metabolism, and it has been shown that the stimulatory or inhibitory effect of $n-6$ or $n-3$ fatty acids in experimental mammary carcinogenesis is abrogated by the addition of the other type of fatty acid [66-68]. Experimental studies have shown that a diet high in $n-6$ fatty acids decreases the concentrations of marine $n-3$ fatty acid-induced lipid peroxidation products in breast cancers to the lowest levels, and that the lower this concentration, the bigger the tumor volumes resulting from n-6 fatty acid administration [52,55]. This experimental evidence is consistent with our results [42] showing that $n-6$ fatty acids increase breast cancer risk only among women with a low intake of marine $n-3$ fatty acids; that is, when concentrations of $n-3$ fatty acid-induced beneficial lipid peroxidation byproducts are low. So one possible mechanism whereby $n-6$ fatty acids increase breast cancer growth is the decreasing of the beneficial lipid peroxidation products derived from $n-3$ fats.

\section{Soy}

At least 13 epidemiological studies have assessed the direct relationship between the individual dietary intake of soy products and the risk of breast cancer (reviewed by Peeters and colleagues [69]). Overall, results do not show protective effects, with the exception maybe for women who consume phytoestrogens at adolescence or at very high doses [70-72]. Only 4 of these 13 studies were prospective, and none of them found statistically significant breast cancer reductions. The only prospective study with urinary measurements taken before breast cancer occurrence was done in a
Dutch postmenopausal population and showed a nonsignificant breast cancer risk reduction for high excretion [73]. Soy phytoestrogen levels in the Dutch study were very low, as were those in another recent study [74]. In conclusion, none of the five prospective studies assessing the effects of phytoestrogens on breast cancer risk found protective effects [69]. However, none of these studies took into account mechanistic pathways by which soy can operate, including the lipid peroxidation pathway, for example, analyzing soy oil, where lipid peroxidation may be higher.

Soybean and canola oils are the primary sources of alpha linolenic acid (ALA; an oxidizable n-3 fatty acid) in the diet [75]. Soybeans contain lipoxygenase, which is an oxidizing enzyme [76] that catalyzes lipid peroxidation [77]. It has been shown that soybean lipooxygenase increases peroxidation of membrane lipids [78] and oxidizes low-density lipoproteins $[12,13,79]$. A soybean oil diet fed to rabbits and rats caused an increase in lipid peroxidation compared to controls [14$16]$; this increase is accenuated by protein insufficiency [17].

Limited in vitro data suggest that the decreased breast cancer risk associated with ALA may be related to increased lipid peroxidation products [18]. The addition of ALA to breast cancer cells caused an increase in the formation of lipid peroxidation products in the cell lipids, and their content was correlated with the capacity of arresting cell growth [18]. The addition of the antioxidant vitamin $E$ to the ALAsupplemented cancer cells diminished formation of lipid hydroperoxides and restored cell growth [18]. In addition, vitamin $E$ also suppressed the inhibitory effect of ALA on tumor growth in different models of mammary carcinogenesis in rats [51]. Administration of oxidative compounds to diets high in ALA led to an inhibition of tumor growth in chemically induced mammary carcinogenesis [51].

In an experimental study, a fermented soymilk product induced generation of ROS and caused apoptotic cell death in MCF-7 breast cancer cells. Growth inhibition and ROS generation induced by fermented soymilk product could be inhibited by catalase and deferoxamine, indicating that the ROS production probably was the cause of this apoptotic cell death [80]. The opposite has also been reported, that is, soy having an antioxidant effect [81]. The effect appears to be indirect as the antioxidant potency of isoflavones is weak and the effects appear to be due more to effects on signaling pathways that induce antioxidant enzyme systems or suppress enzymes that produce ROS.

\section{Isothiocyanates}

In animal models of breast cancer, tumor growth is inhibited by brassica consumption, or ITC or indole-3-carbinol administration [82-85]. In humans, the relationship between brassica consumption and breast cancer risk is uncertain. Investigations have found null associations [86-89], protective but not statistically significant associations [90-92], and statistically 
significant protective associations [93,94]. The failure to consider the lipid peroxidation pathway and the implied modifying effects of oxidative stress-related genes may explain the lack of consistency among human studies. ITCs are potent inducers of lipid peroxidation [20-23]. There is suggestive evidence that ITC-induced apoptosis is mediated by oxidative stress/lipid peroxidation products [22,23]. Depletion of the antioxidant glutathione significantly accelerated ITCtriggered apoptosis [23]. ITCs are also able to induce glutathione $S$-transferases (GSTs) and/or other antioxidant enzymes through the stress-signaling pathway involving oxidative stress [22]. Oxidizing agents enhanced ITC-induced ROS production and ITC-induced GST activities, whereas antioxidants inhibited both [22]. In humans, one study has shown that individuals with genetic polymorphisms encoding lower or no activity in antioxidant enzymes (GSTM1, GSTT1) experience more breast cancer protection from ITCs than those with common alleles [95], putatively because more beneficial peroxidation agents could reach the cancer cells and cause damage (see below). However, this finding has not been confirmed in a second study [94].

\section{Tea}

Published epidemiological studies overall suggest that green tea but not black tea consumption is related to decreased risk of breast cancer [96]. A recent meta-analysis [96] included three cohort and one population-based study for green tea, while five cohort and eight case-control studies were analyzed for a link between black tea and breast cancer. Overall summary odds ratio showed an approximately $20 \%$ statistically significant reduction in risk of breast cancer associated with high intake of green tea. No such protective effect was found for black tea.

Both green and black tea have demonstrated inhibitory activities against chemically induced mammary tumors in experimental animals [97-99]. Epigallocatechin gallate (EGCG), one of the main constituents of tea that is thought to be responsible for its anticancer properties, not only can function as an antioxidant, but it possesses the chemical property of a pro-oxidant. Previous studies on the antioxidative properties of EGCG have demonstrated that its effects include both trapping of ROS as well as inhibition of lipid peroxidation [25]. However, after neutralizing the peroxyl and/or other radicals, EGCG itself could be converted to a phenoxyl radical [26]. Experimental studies in HT-29 colorectal cancer cells have indicated that oxidative stress is involved in EGCG-induced cell death. The chemical property of EGCG as a potential pro-oxidant is highlighted by the blocking effects of reduced glutathione and $\mathrm{N}$-acetyl-L-cysteine against EGCG-induced mitogen-activated protein kinase activation, cytochrome c release and cell death [24]. In a recent study [100], Wu and colleagues noted that the protective effect of tea on breast cancer was confined to those possessing the low-activity genotype of the antioxidant catechol-O-methyl transferase (COMT), putatively because more beneficial peroxidation agents could reach the cancer cells and cause damage.

\section{Vitamin D and calcium}

Increased mammographic breast density is strongly associated with the risk of breast cancer [101]. A recent study showed that an increased intake of vitamin $D$ and calcium was associated with decreases in mammographic breast density [102].

Evidence from both in vitro and in vivo studies has demonstrated that vitamin D compounds can inhibit the growth of breast cancer cells [103]. The anticancer activity of the hormonal form of vitamin D, 1,25-dihydroxycholecalciferol $\left(1,25-(\mathrm{OH})_{2} \mathrm{D}_{3}\right)$ [104], is associated with inhibition of cell cycle progression, induction of differentiation, and apoptosis. In addition, $1,25(\mathrm{OH})_{2} \mathrm{D}_{3}$ may exert some of its activity by cooperating with other anticancer agents. $1,25(\mathrm{OH})_{2} \mathrm{D}_{3}$ and its synthetic analogues increased the susceptibility of cancer cells to the cytotoxic/cytostatic action of tumor necrosis factor [105-107], interleukin 1, interleukin 6 [108], doxorubicin, menadione [109], and radiation [110]. A feature shared by these agents whose potency is increased by $1,25(\mathrm{OH})_{2} \mathrm{D}_{3}$ is their ability to bring about excessive ROS generation in their target cells [111-113]. This common feature suggests the involvement of ROS in the interaction between $1,25(\mathrm{OH})_{2} \mathrm{D}_{3}$ and these agents. In addition, the potentiation of the cytotoxic/cytostatic action of the chemotherapy drug doxorubicin or cytokines by $1,25(\mathrm{OH})_{2} \mathrm{D}_{3}$ is markedly inhibited by the antioxidant $\mathrm{N}$-actylcysteine $[108,109]$. Importantly, it has recently been shown that $1,25(\mathrm{OH})_{2} \mathrm{D}_{3}$, acting as a single agent, is also a pro-oxidant in cancer cells [29]. These findings indicate that $1,25(\mathrm{OH})_{2} \mathrm{D}_{3}$ causes an increase in the overall cellular redox potential that could translate into modulation of redoxsensitive enzymes and transcription factors that regulate cell cycle progression, differentiation, and apoptosis [29].

The evidence that calcium or dairy products are associated with breast cancer risk is still open to debate. A recent pooled analysis of cohort studies failed to find an association [114], but some studies found some limited evidence of a protection $[115,116]$. As mentioned above, a recent study showed that an increased intake of vitamin $D$ and calcium was associated with decreases in mammographic breast density [102]. Boyapati and colleagues [116] recently reported that dietary calcium intake was negatively associated with the risk of breast cancer in both premenopausal and postmenopausal women. In the Nurses' Health Study both calcium and dairy product intake was associated with a survival benefit for women with breast cancer $[117,118]$.

After ingestion, calcium absorption can occur via an active transport process (transcellular) that requires the action of $1,25-(\mathrm{OH})_{2} \mathrm{D}_{3}$, or by passive diffusion (paracellular), which is a vitamin-D-independent process. The vast majority of 
calcium absorption (77\% to $92 \%$ ) relies upon the transcellular pathway, and thus upon the activity of $1,25-(\mathrm{OH})_{2} \mathrm{D}_{3}$ [119]. Therefore, it is difficult to separately establish the potential effects of these two nutrients on health and disease, and it is of clear importance to evaluate the effects of these nutrients simultaneously [120].

There are several proposed mechanisms of action for calcium, including inhibition of cellular proliferation [121,122], and induction of apoptotic cell death [123,124] through oxidative stress $[30,31,125,126]$. It is, however, unclear how calcium, especially through intake, might have these hypothesized effects when blood levels are so tightly regulated. It seems that the elevation in the intracellular free calcium, which correlates with the induction of apoptosis in breast cancer cells, is brought about by vitamin D compounds [124,127-129]. The latter studies further support the need for investigations that consider the role of vitamin D and calcium simultaneously. The effects of these two nutrients may be strongly related to one another, and separate studies may not capture their true effects on breast neoplasia. Generally, apoptotic cell death is triggered by intracellular signaling pathways, including a rise in intracellular free calcium [30], the generation of ROS and membrane lipid peroxidation products $[125,126]$. Calcium strongly stimulates the release of ROS [130] (including superoxide anion [131133], hydrogen peroxide and hydroxyl radicals [134]), which induce membrane lipid peroxidation [130]. This calciumdependent increase in membrane lipid peroxidation triggers apoptotic cell death $[30,31,125,126]$. Calcium, lipid peroxidation and apoptosis are possibly interlinked through signals, as is evident from the increased activity of nuclear factor kappa-B, a critical molecule in oxidative-stress-induced apoptosis, and generation of nitric oxide [135].

\section{Oxidative stress metabolism: modifying effect of oxidative stress genes on the relationships between dietary factors and breast cancer}

If lipid peroxidation/ROS plays a role in breast cancer protection, it is likely that differences in the ability to protect cells from these beneficial products will determine, to some degree, the effect of these protective factors on breast cancer. Critical to the effects of products of lipid peroxidation are the enzymatic and non-enzymatic defenses that protect the cells from oxidative stress through reduction of reactive molecules, including mitochondrial manganese superoxide dismutase (MnSOD), glutathione peroxidase, and catalase. These enzymes form the first line of defense against superoxide and hydrogen peroxide [136]. The resultant secondary oxidation products may still damage DNA, proteins and lipid, and require further detoxification. This second line of defense against ROS/lipid peroxidation is provided by enzymes such as the GSTs. Several examples support a modifying effect of oxidative stress genes on the relationships between dietary factors and breast cancer.
We will summarize next the potential modifying roles of oxidative stress genes on the relationships between n-3 fatty acids, ITCs, and tea and breast cancer.

\section{Glutathione S-transferases GSTM1, GSTT1, and GSTP1}

Glutathione-associated metabolism is a major mechanism for cellular protection against agents that generate oxidative stress, protecting cells against cytotoxic products of lipid peroxidation $[58,59]$. GSTs are induced under conditions of oxidative stress, and alpha-, pi-, mu-, and theta-class GSTs are active in detoxification of numerous products, including reactive oxidant damage to DNA and lipids, such as organic epoxides, lipid hydroperoxides, and unsaturated aldehydes $[58,59]$. Individuals lacking these enzymes may have reduced removal of lipid peroxidation products and, thus, may experience higher cancer protection, as supported by results from our study [19]. We found that women with genetic polymorphisms causing lower or no activity in detoxifying genes (GSTM1, GSTT1, GSTP1) had more protection from marine n-3 fatty acids than those with common alleles, putatively because more cytotoxic peroxidation agents could reach the cancerous and pre-cancerous cells and cause damage. Recent results on cyclin D1 (CCND1), an intracellular cell-cycle regulatory protein with checkpoint function, and breast cancer risk further support our hypothesis of an oxidative stress-induced apoptosis mechanism underlying the diet-induced breast cancer protection. CCND1 has been shown to modulate growth arrest and apoptosis following exposure to ionizing radiation oxidative DNA damage $[137,138]$. In a recent study, the protective effect of the heterozygous CCND1 GA genotype on breast cancer risk was restricted to situations of elevated oxidative stress, characterized by absence of antioxidant GSTM1 and GSTT1 enzymes [139]. In addition, CCND1 also interacted with marine n-3 and n- 6 fatty acids to influence breast cancer risk, with the protection being restricted to women with a high intake level of n-6 fatty acids, or a low intake level of marine n3 fatty acids [139].

Similarly, ITCs' protective effect on breast cancer found in some studies [95], although not in others [94], was mainly confined to those possessing the low activity genotype of GSTs. There is suggestive evidence that ITC-induced apoptosis is mediated by oxidative stress/lipid peroxidation products $[22,23]$. Seow and colleagues [140] also found that individuals with genetic polymorphisms causing lower or no activity in antioxidant genes (GSTM1, GSTT1, GSTP1) had more colorectal cancer protection from ITCs than those with common alleles. These findings were attributed to the direct effects of GSTs on ITC excretion [140]. However, we proposed that the oxidative products of ITCs may be responsible, at least in part, for their anti-cancer effect, and this would explain why the protection appears more pronounced among subjects with lowest antioxidant GST activity [11], in parallel with what we had described for the marine n-3 fatty acids/GST/breast cancer relationship [19]. A 
subsequent colon cancer study, in which the effect of the CCND1 A870G polymorphism on colorectal cancer risk was found to be modified by GSTM1, GSTT1, and GSTP1 genotypes and ITC intake [141], further supports our proposed oxidative stress-based hypothesis. In that study, the presence of at least one CCND1 A-allele was associated with increased risk among low dietary ITC consumers with a high activity GST profile. In contrast, the presence of at least one A-allele was associated with a decreased risk among all remaining subjects, which led the investigators to hypothesize that subjects with low intake levels of ITCs and functional GST enzymes are left with low levels of prooxidative, anti-cancer acting ITCs at a cellular level [141].

The genetic polymorphisms of GSTM1 and GSTT1 have also been found to influence the risk-enhancing effect of alcohol in breast cancer. Zheng and colleagues [142] found that breast cancer risk was about 7-fold increased for postmenopausal women with the GSTT1-null genotype who consumed more than $250 \mathrm{~kg}$ of spirit equivalents. In our prior study [19], the GSTT1-null genotype was associated with a $30 \%$ reduced risk of breast cancer. This finding is consistent with another study that reported a decreased risk among premenopausal women lacking the GSTT1 gene [60]. Most studies have found no increased risk for breast cancer with null genotypes for GSTM1 and/or GSTT1 (reviewed in [61]), although some positive associations have been reported [143-147].

\section{Catechol-O-methyl transferase}

COMT is an antioxidant enzyme that catalyses the methylation of hydroxylated sites on the aromatic ring of catechol compounds, which prevents their conversion to semiquinones and quinines and, therefore, blocks the generation of ROS [148-150]. In a recent study, the COMT-L low activity allelecontaining genotypes ( $H L$ or $L L$ ) tended to be at decreased risk of developing breast cancer, especially the advanced stage of disease in premenopausal women and local carcinoma in postmenopausal women $[151,152]$. A tendency of decreasing risk can also be seen for both pre- and postmenopausal women in the study of Millikan and colleagues [153]. Similarly, in the case-control study of Lavigne and colleagues [154], a tendency of decreasing risk was seen among premenopausal women, although the results were based on a rather small number of subjects. Thompson and colleagues [155] observed increased risk for premenopausal women carrying the COMT- $L$ allele-containing genotypes and decreased risk for postmenopausal women with these genotypes. Among Asian-American women in Los Angeles, the protective effect of tea in breast cancer was mainly confined to those possessing the low activity genotype of COMT [100]. A recent study was conducted among breast cancer families participating in the Metropolitan New York Registry, one of the six centers of the Breast Cancer Family Registry [156]. The study found that COMT genotypes were not statistically significantly associated with breast cancer risk, although the study population was of modest size (160 sib-ships).

\section{Manganese superoxide dismutase}

MnSOD is an antioxidant enzyme that is induced by free radical challenge, such as marine $n-3$ fatty acid-induced lipid peroxidation [136,157,158], and inhibits polyunsaturated fatty acid-induced lipid peroxidation and the subsequent killing of human breast cancer cells [159]. In the mitochondrion, MnSOD catalyzes the dismutation of two superoxide radicals, producing hydrogen peroxide and oxygen. A substitution variant in the mitochondrial targeting sequence was found that changes the amino acid codon at the -9 position in the signal peptide from valine to alanine [160-162]. Hiroi and colleagues [163] reported that processing efficiency of the valine-type SOD leader peptide in the presence of mitochondria was significantly lower than that of the alanine-type, which may reduce protection against superoxide radicals. This decrease in the efficiency of transport into mitochondria for the valine isoform of the protein may result in increased ROS [160,163]. An association between the valine allele with lung cancer risk has been reported in a recent study [164]. Contrarily, an association between the alanine allele and risk of breast cancer has been found in three studies, two conducted in the US [162,165] and one in Finland [166]. In the study by Ambrosone and coworkers [162], premenopausal women who were homozygous for the alanine allele had a four-fold increase in breast cancer risk in comparison to those with one or two valine alleles [162]. Risk was most pronounced among women who consumed below the median amount of fruit and vegetables and of ascorbic acid and $\alpha$-tocopherol. In addition, in the Finnish study, MnSOD genotypes containing the alanine allele were found to be associated with a 1.5-fold $(95 \% \mathrm{Cl}=1.1,2.0)$ increased risk of breast cancer compared with those homozygous for the valine/valine genotype [166]. The association between this polymorphism and breast cancer risk was weaker in the other US study (odds ratio = $1.27 ; 95 \% \mathrm{Cl}=0.91,1.77$ ) [165], and no association was found in a case-control study within the Breast Cancer Family Registry [167]. However, recent results suggest that this polymorphism is also associated with breast cancer risk among Chinese in Shanghai [168].

\section{Conclusion}

Accumulating evidence suggests that oxidative stressinduced apoptosis may play an important role in the anticarcinogenic effect of several chemopreventive agents, including retinoids, nonsteroidal anti-inflammatory drugs, polyphenols, tamoxifen, vanilloids, and rotenoids [169]. In this review, we describe how several breast cancer chemopreventive factors may exert their anti-cancer effect through lipid peroxidation-induced apoptosis, including marine $n-3$ fatty acids, soy, ITCs, vitamin D and calcium. We also describe the modifying effect of oxidative stress-related genes such as GSTM1, GSTT1, GSTP1, CNDN1, and COMT in the relationships between marine n-3 fatty acids, ITCs, and tea and breast cancer. We believe that the lack of consideration of the lipid peroxidation pathway and the 
implied modifying effects of related gene polymorphisms may account for some of the lack of consistency in previous epidemiological studies of diet and breast cancer. In addition, because several of the dietary factors discussed in this manuscript have been shown to have multiple cellular effects, not only lipid peroxidation-related effects, we believe that it will be important to study the cross-talk between the lipid peroxidation pathway and other pathways, such as estrogen, insulin resistance, inflammation, and possibly other pathways. The lipid peroxidation hypothesis might be further investigated by measuring the levels of lipid peroxidation markers such as F2 isoprostanes, which comprise the 'gold standard' marker of oxidative stress in vivo, in fluid nipple aspirate or breast tissue of women with breast cancer, and compare the values with those from control women.

Our hypothesis has practical implications for breast cancer prevention. Lipid peroxidation could be proven to be a prediagnostic marker for breast cancer. Lipid peroxidation levels in breast ductal cells may represent a promising cancer biomarker to detect, through non-invasive methods such as nipple fluid aspirate sampling, for example, women at high risk for breast cancer. In addition, a better understanding of the relationship between breast cancer risk factors and oxidative stress/lipid peroxidation-related biomarkers and genes may prove useful in identifying the dietary or non-dietary exposuregenotype combinations that put women at the lowest risk. In addition, lipid peroxidation markers could also be used as indicators of prognosis. Decreased plasma malondialdehyde (MDA), another lipid peroxidation marker, has been found to be significantly associated with severity of prognosis factors for breast cancer. MDA concentrations were significantly lower in the plasma of patients with large tumors or in whom nodes and/or metastasis were present [170-172].

\section{Competing interests}

The authors declare that they have no competing interests.

\section{Acknowledgements}

This work was supported by grant R01 CA114472 from the United States National Cancer Institute, Bethesda, Maryland.

\section{References}

1. Shewfelt RL, Purvis AC: Toward a comprehensive model for lipid peroxidation in plant tissue disorders. HortScience 1995, 20:213-218.

2. Blokhina O, Virolainen E, Fagerstedt KV: Antioxidants, oxidative damage and oxygen deprivation stress: a review. Ann Bot (Lond) 2003, 91 Spec No:179-194.

3. Tarchevskii I: Regulatory role of degradation of biopolymers and lipids. Fiziologiya Rastenii 1992, 39:1215-1223.

4. Cejas P, Casado E, Belda-Iniesta C, De Castro J, Espinosa E, Redondo A, Sereno M, Garcia-Cabezas MA, Vara JA, DominguezCaceres $A$, et al:: Implications of oxidative stress and cell membrane lipid peroxidation in human cancer (Spain). Cancer Causes Control 2004, 15:707-719.

5. Barrera G, Pizzimenti S, Dianzani MU: 4-hydroxynonenal and regulation of cell cycle: effects on the pRb/E2F pathway. Free Radic Biol Med 2004, 37:597-606.

6. Fazio VM, Rinaldi M, Ciafre S, Barrera G, Farace MG: Control of neoplastic cell proliferation and differentiation by restoration of 4-hydroxynonenal physiological concentrations. Mol Aspects Med 1993, 14:217-228.

7. Das UN: Essential fatty acids, lipid peroxidation and apoptosis. Prostaglandins Leukot Essent Fatty Acids 1999, 61:157-163.

8. Das U: A radical approach to cancer. Med Sci Monit 2002, 8:RA79-92.

9. Kalinich JF, Ramakrishnan R, McClain DE, Ramakrishnan N: 4Hydroxynonenal, an end-product of lipid peroxidation, induces apoptosis in human leukemic T- and B-cell lines. Free Radic Res 2000, 33:349-358.

10. Salganik RI: The benefits and hazards of antioxidants: controlling apoptosis and other protective mechanisms in cancer patients and the human population. J Am Coll Nutr 2001, 20 (Suppl 5):464S-472S; discussion 473S-475S.

11. Gago-Dominguez M, Castelao JE, Pike MC, Sevanian A, Haile RW: Role of lipid peroxidation in the epidemiology and prevention of breast cancer. Cancer Epidemiol Biomarkers Prev 2005, 14:2829-2839.

12. O'Leary VJ, Graham A, Stone D, Darley-Usmar VM: Oxidation of human low-density lipoprotein by soybean 15-lipoxygenase in combination with copper (II) or met-myoglobin. Free Radic Biol Med 1996, 20:525-532.

13. Upston JM, Neuzil J, Witting PK, Alleva R, Stocker R: Oxidation of free fatty acids in low density lipoprotein by 15-lipoxygenase stimulates nonenzymic, alpha-tocopherol-mediated peroxidation of cholesteryl esters. J Biol Chem 1997, 272: 30067-30074.

14. Greco AV, Mingrone G: Serum and biliary lipid pattern in rabbits feeding a diet enriched with unsaturated fatty acids. Exp Pathol 1990, 40:19-33.

15. Lopes LR, Laurindo FR, Mancini-Filho J, Curi R, Sannomiya P: NADPH-oxidase activity and lipid peroxidation in neutrophils from rats fed fat-rich diets. Cell Biochem Funct 1999, 17:5764.

16. Yap SC, Choo YM, Hew NF, Yap SF, Khor HT, Ong AS, Goh SH: Oxidative susceptibility of low density lipoprotein from rabbits fed atherogenic diets containing coconut, palm, or soybean oils. Lipids 1995, 30:1145-1150.

17. Huang CJ, Fwu ML: Protein insufficiency aggravates the enhanced lipid peroxidation and reduced activities of antioxidative enzymes in rats fed diets high in polyunsaturated fat. $J$ Nutr 1992, 122:1182-1189.

18. Chajes V, Sattler W, Stranzl A, Kostner GM: Influence of n-3 fatty acids on the growth of human breast cancer cells in vitro: relationship to peroxides and vitamin-E. Breast Cancer Res Treat 1995, 34:199-212.

19. Gago-Dominguez M, Castelao JE, Sun CL, Van Den Berg D, Koh WP, Lee HP, Yu MC: Marine n-3 fatty acid intake, glutathione $\mathrm{S}$-transferase polymorphisms and breast cancer risk in postmenopausal Chinese women in Singapore. Carcinogenesis 2004, 25:2143-2147.

20. Kassie F, Pool-Zobel B, Parzefall W, Knasmuller S: Genotoxic effects of benzyl isothiocyanate, a natural chemopreventive agent. Mutagenesis 1999, 14:595-604.

21. Kassie F, Laky B, Nobis E, Kundi M, Knasmuller S: Genotoxic effects of methyl isothiocyanate. Mutat Res 2001, 490:1-9.

22. Nakamura $Y$, Ohigashi $H$, Masuda $S$, Murakami A, Morimitsu $Y$, Kawamoto Y, Osawa T, Imagawa M, Uchida K: Redox regulation of glutathione S-transferase induction by benzyl isothiocyanate: correlation of enzyme induction with the formation of reactive oxygen intermediates. Cancer Res 2000, 60:219-225.

23. Nakamura $Y$, Kawakami M, Yoshihiro A, Miyoshi N, Ohigashi $H$, Kawai K, Osawa T, Uchida K: Involvement of the mitochondrial death pathway in chemopreventive benzyl isothiocyanateinduced apoptosis. $J$ Biol Chem 2002, 277:8492-8499.

24. Chen C, Shen G, Hebbar V, Hu R, Owuor ED, Kong AN: Epigallocatechin-3-gallate-induced stress signals in HT-29 human colon adenocarcinoma cells. Carcinogenesis 2003, 24:13691378.

25. Wiseman SA, Balentine DA, Frei B: Antioxidants in tea. Crit Rev Food Sci Nutr 1997, 37:705-718.

26. Valcic S, Muders A, Jacobsen NE, Liebler DC, Timmermann BN: Antioxidant chemistry of green tea catechins. Identification of products of the reaction of (-)-epigallocatechin gallate with peroxyl radicals. Chem Res Toxicol 1999, 12:382-386.

27. Hong J, Lu H, Meng $X$, Ryu JH, Hara Y, Yang CS: Stability, cellular uptake, biotransformation, and efflux of tea poly- 
phenol (-)-epigallocatechin-3-gallate in HT-29 human colon adenocarcinoma cells. Cancer Res 2002, 62:7241-7246.

28. Yang CS, Maliakal $P$, Meng $X$ : Inhibition of carcinogenesis by tea. Annu Rev Pharmacol Toxicol 2002, 42:25-54.

29. Koren R, Hadari-Naor I, Zuck E, Rotem C, Liberman UA, Ravid A: Vitamin D is a prooxidant in breast cancer cells. Cancer Res 2001, 61:1439-1444.

30. Kruman I, Guo Q, Mattson MP: Calcium and reactive oxygen species mediate staurosporine-induced mitochondrial dysfunction and apoptosis in PC12 cells. J Neurosci Res 1998, 51: 293-308.

31. Shakhman O, Herkert M, Rose C, Humeny A, Becker CM: Induction by beta-bungarotoxin of apoptosis in cultured hippocampal neurons is mediated by $\mathrm{Ca}(2+)$-dependent formation of reactive oxygen species. J Neurochem 2003, 87:598-608.

32. Gago-Dominguez M, Castelao JE, Yuan JM, Ross RK, Yu MC: Lipid peroxidation: a novel and unifying concept of the etiology of renal cell carcinoma (United States). Cancer Causes Control 2002, 13:287-293.

33. Gago-Dominguez M, Castelao JE: Lipid peroxidation and renal cell carcinoma: further supportive evidence and new mechanistic insights. Free Radic Biol Med 2006, 40:721-733.

34. Greenland S, Gago-Dominguez M, Castelao JE: The value of risk-factor ("black-box") epidemiology. Epidemiology 2004, 15: 529-535.

35. Vatten LJ, Solvoll K, Loken EB: Frequency of meat and fish intake and risk of breast cancer in a prospective study of 14,500 Norwegian women. Int J Cancer 1990, 46:12-15.

36. Key TJ, Sharp GB, Appleby PN, Beral V, Goodman MT, Soda M, Mabuchi K: Soya foods and breast cancer risk: a prospective study in Hiroshima and Nagasaki, Japan. Br J Cancer 1999, 81:1248-1256.

37. Engeset D, Alsaker $E$, Lund $E$, Welch A, Khaw KT, ClavelChapelon F, Thiebaut A, Chajes V, Key TJ, Allen NE, et al:: Fish consumption and breast cancer risk. The European Prospective Investigation into Cancer and Nutrition (EPIC). Int J Cancer 2006, 119:175-182.

38. Toniolo P, Riboli E, Shore RE, Pasternack BS: Consumption of meat, animal products, protein, and fat and risk of breast cancer: a prospective cohort study in New York. Epidemiology 1994, 5:391-397.

39. Holmes MD, Hunter DJ, Colditz GA, Stampfer MJ, Hankinson SE, Speizer FE, Rosner B, Willett WC: Association of dietary intake of fat and fatty acids with risk of breast cancer. JAMA 1999, 281:914-920.

40. Gertig DM, Hankinson SE, Hough H, Spiegelman D, Colditz GA, Willett WC, Kelsey KT, Hunter DJ: N-acetyl transferase 2 genotypes, meat intake and breast cancer risk. Int J Cancer 1999, 80:13-17.

41. Stampfer MJ, Willett WC, Colditz GA, Speizer FE: Intake of cholesterol, fish and specific types of fat in relation to risk of breast cancer. In Proceedings of the AOCS Short Course on Polyunsaturated Fatty Acids and Eicosanoids: 13-16 May 1987; Champaign, IL. Edited by Lands WE. American Oil Chemists' Society: Biloxi, Mississippi; 1987:248-252.

42. Gago-Dominguez M, Yuan JM, Sun CL, Lee HP, Yu MC: Opposing effects of dietary n-3 and n-6 fatty acids on mammary carcinogenesis: The Singapore Chinese Health Study. $\mathrm{Br} J$ Cancer 2003, 89:1686-1692.

43. Zhu ZR, Agren J, Mannisto S, Pietinen P, Eskelinen M, Syrjanen K, Uusitupa M: Fatty acid composition of breast adipose tissue in breast cancer patients and in patients with benign breast disease. Nutr Cancer 1995, 24:151-160.

44. Simonsen N, van't Veer $P$, Strain JJ, Martin-Moreno JM, Huttunen JK, Navajas JF, Martin BC, Thamm M, Kardinaal AF, Kok FJ, et al.: Adipose tissue omega-3 and omega- 6 fatty acid content and breast cancer in the EURAMIC study. European Community Multicenter Study on Antioxidants, Myocardial Infarction, and Breast Cancer. Am J Epidemiol 1998, 147:342-352.

45. Maillard V, Bougnoux P, Ferrari $P$, Jourdan ML, Pinault M, Lavillonniere F, Body G, Le Floch O, Chajes V: N-3 and N-6 fatty acids in breast adipose tissue and relative risk of breast cancer in a case-control study in Tours, France. Int J Cancer 2002, 98:7883.

46. Petrek JA, Hudgins LC, Levine B, Ho M, Hirsch J: Breast cancer risk and fatty acids in the breast and abdominal adipose tissues. J Natl Cancer Inst 1994, 86:53-56.
47. London SJ, Sacks FM, Stampfer MJ, Henderson IC, Maclure M, Tomita A, Wood WC, Remine S, Robert NJ, Dmochowski JR, et al.: Fatty acid composition of the subcutaneous adipose tissue and risk of proliferative benign breast disease and breast cancer. J Nat/ Cancer Inst 1993, 85:785-793.

48. Bougnoux $P: n-3$ polyunsaturated fatty acids and cancer. Curr Opin Clin Nutr Metab Care 1999, 2:121-126.

49. Stoll BA: N-3 fatty acids and lipid peroxidation in breast cancer inhibition. Br J Nutr 2002, 87:193-198.

50. Stoll BA: Breast cancer and the western diet: role of fatty acids and antioxidant vitamins. Eur J Cancer 1998, 34:18521856.

51. Cognault S, Jourdan ML, Germain E, Pitavy R, Morel E, Durand G, Bougnoux $P$, Lhuillery $C$ : Effect of an alpha-linolenic acid-rich diet on rat mammary tumor growth depends on the dietary oxidative status. Nutr Cancer 2000, 36:33-41.

52. Gonzalez MJ, Schemmel RA, Dugan L Jr, Gray Jl, Welsch CW: Dietary fish oil inhibits human breast carcinoma growth: a function of increased lipid peroxidation. Lipids 1993, 28:827-832.

53. Willett WC: Specific fatty acids and risks of breast and prostate cancer: dietary intake. Am J Clin Nutr 1997, 66(Suppl 6):1557S-1563S.

54. Nesheim MC: What is the research base for the use of dietary supplements? Public Health Nutr 1999, 2:35-38.

55. Gonzalez MJ, Schemmel RA, Gray JI, Dugan L Jr, Sheffield LG, Welsch CW: Effect of dietary fat on growth of MCF-7 and MDA-MB231 human breast carcinomas in athymic nude mice: relationship between carcinoma growth and lipid peroxidation product levels. Carcinogenesis 1991, 12:1231-1235.

56. Welsch CW: Review of the effects of dietary fat on experimental mammary gland tumorigenesis: role of lipid peroxidation. Free Radic Biol Med 1995, 18:757-773.

57. Welsch C: The role of lipid peroxidation in growth suppression of human breast carcinoma by dietary fish oil. Adv Exp Med Biol 1997, 400B:849-860.

58. Ambrosone CB, Sweeney C, Coles BF, Thompson PA, McClure GY, Korourian S, Fares MY, Stone A, Kadlubar FF, Hutchins LF: Polymorphisms in glutathione S-transferases (GSTM1 and GSTT1) and survival after treatment for breast cancer. Cancer Res 2001, 61:7130-7135.

59. Hayes JD, McLellan LI: Glutathione and glutathione-dependent enzymes represent a co-ordinately regulated defence against oxidative stress. Free Radic Res 1999, 31:273-300.

60. Garcia-Closas M, Kelsey KT, Hankinson SE, Spiegelman D, Springer K, Willett WC, Speizer FE, Hunter DJ: Glutathione Stransferase mu and theta polymorphisms and breast cancer susceptibility. J Nat/ Cancer Inst 1999, 91:1960-1964.

61. Dunning AM, Healey CS, Pharoah PD, Teare MD, Ponder BA, Easton DF: A systematic review of genetic polymorphisms and breast cancer risk. Cancer Epidemiol Biomarkers Prev 1999, 8: 843-854.

62. Hunter DJ, Spiegelman D, Adami HO, Beeson L, van den Brandt PA, Folsom AR, Fraser GE, Goldbohm RA, Graham S, Howe GR, et al:: Cohort studies of fat intake and the risk of breast cancer - a pooled analysis. N Engl J Med 1996, 334:356-361.

63. Harrison RA, Waterbor JW: Understanding meta-analysis in cancer epidemiology: dietary fat and breast cancer. Cancer Detect Prev 1999, 23:97-106.

64. Smith-Warner SA, Spiegelman D, Adami HO, Beeson WL, van den Brandt PA, Folsom AR, Fraser GE, Freudenheim JL, Goldbohm RA, Graham S, et al:: Types of dietary fat and breast cancer: a pooled analysis of cohort studies. Int J Cancer 2001, 92:767-774.

65. Fay MP, Freedman LS, Clifford CK, Midthune DN: Effect of different types and amounts of fat on the development of mammary tumors in rodents: a review. Cancer Res 1997, 57: 3979-3988.

66. Gabor H, Abraham S: Effect of dietary menhaden oil on tumor cell loss and the accumulation of mass of a transplantable mammary adenocarcinoma in BALB/c mice. J Natl Cancer Inst 1986, 76:1223-1229.

67. Karmali RA, Marsh J, Fuchs C: Effect of omega-3 fatty acids on growth of a rat mammary tumor. J Natl Cancer Inst 1984, 73: 457-461.

68. Rose DP, Connolly JM: Effects of dietary omega-3 fatty acids on human breast cancer growth and metastases in nude mice. J Natl Cancer Inst 1993, 85:1743-1747. 
69. Peeters PH, Keinan-Boker L, van der Schouw YT, Grobbee DE: Phytoestrogens and breast cancer risk. Review of the epidemiological evidence. Breast Cancer Res Treat 2003, 77:171183.

70. Wu AH, Ziegler RG, Horn-Ross PL, Nomura AM, West DW, Kolonel LN, Rosenthal JF, Hoover RN, Pike MC: Tofu and risk of breast cancer in Asian-Americans. Cancer Epidemiol Biomarkers Prev 1996, 5:901-906.

71. Witte JS, Ursin G, Siemiatycki J, Thompson WD, Paganini-Hill A, Haile RW: Diet and premenopausal bilateral breast cancer: a case-control study. Breast Cancer Res Treat 1997, 42:243-251.

72. Shu XO, Jin F, Dai Q, Wen W, Potter JD, Kushi LH, Ruan Z, Gao YT, Zheng W: Soyfood intake during adolescence and subsequent risk of breast cancer among Chinese women. Cancer Epidemiol Biomarkers Prev 2001, 10:483-488.

73. den Tonkelaar I, Keinan-Boker L, Veer PV, Arts CJ, Adlercreutz H, Thijssen JH, Peeters $\mathrm{PH}$ : Urinary phytoestrogens and postmenopausal breast cancer risk. Cancer Epidemiol Biomarkers Prev 2001, 10:223-228.

74. Grace PB, Taylor Jl, Low YL, Luben RN, Mulligan AA, Botting NP, Dowsett M, Welch AA, Khaw KT, Wareham NJ, et al:: Phytoestrogen concentrations in serum and spot urine as biomarkers for dietary phytoestrogen intake and their relation to breast cancer risk in European prospective investigation of cancer and nutrition-norfolk. Cancer Epidemiol Biomarkers Prev 2004, 13:698-708.

75. Kris-Etherton PM, Taylor DS, Yu-Poth S, Huth P, Moriarty K, Fishell V, Hargrove RL, Zhao G, Etherton TD: Polyunsaturated fatty acids in the food chain in the United States. Am J Clin Nutr 2000, 71(Suppl 1):179S-188S.

76. Masini E, Palmerani B, Gambassi F, Pistelli A, Giannella E, Occupati B, Ciuffi M, Sacchi TB, Mannaioni PF: Histamine release from rat mast cells induced by metabolic activation of polyunsaturated fatty acids into free radicals. Biochem Pharmacol 1990, 39:879-889.

77. Naidu KA: Eugenol - an inhibitor of lipoxygenase-dependent lipid peroxidation. Prostaglandins Leukot Essent Fatty Acids 1995, 53:381-383.

78. Parinandi NL, Zwizinski CW, Schmid $\mathrm{HH}$ : Free radical-induced alterations of myocardial membrane proteins. Arch Biochem Biophys 1991, 289:118-123.

79. Subbaiah PV, Subramanian VS, Wang K: Novel physiological function of sphingomyelin in plasma. Inhibition of lipid peroxidation in low density lipoproteins. J Biol Chem 1999, 274: 36409-36414.

80. Chang WH, Liu JJ, Chen $\mathrm{CH}$, Huang TS, Lu FJ: Growth inhibition and induction of apoptosis in MCF-7 breast cancer cells by fermented soy milk. Nutr Cancer 2002, 43:214-226.

81. Rufer CE, Kulling SE: Antioxidant activity of isoflavones and their major metabolites using different in vitro assays. J Agric Food Chem 2006, 54:2926-2931.

82. Grubbs CJ, Steele VE, Casebolt T, Juliana MM, Eto I, Whitaker LM, Dragnev KH, Kelloff GJ, Lubet RL: Chemoprevention of chemically-induced mammary carcinogenesis by indole-3carbinol. Anticancer Res 1995, 15:709-716.

83. Wattenberg LW: Inhibition of carcinogen-induced neoplasia by sodium cyanate, tert-butyl isocyanate, and benzyl isothiocyanate administered subsequent to carcinogen exposure. Cancer Res 1981, 41:2991-2994.

84. Bresnick E, Birt DF, Wolterman K, Wheeler M, Markin RS: Reduction in mammary tumorigenesis in the rat by cabbage and cabbage residue. Carcinogenesis 1990, 11:1159-1163.

85. Stoewsand GS, Anderson JL, Munson L: Protective effect of dietary brussels sprouts against mammary carcinogenesis in Sprague-Dawley rats. Cancer Lett 1988, 39:199-207.

86. Franceschi S, Parpinel M, La Vecchia C, Favero A, Talamini R, Negri E: Role of different types of vegetables and fruit in the prevention of cancer of the colon, rectum, and breast. Epidemiology 1998, 9:338-341.

87. Graham S, Marshall J, Mettlin C, Rzepka T, Nemoto T, Byers T: Diet in the epidemiology of breast cancer. Am J Epidemiol 1982, 116:68-75.

88. Katsouyanni K, Trichopoulos D, Boyle P, Xirouchaki E, Trichopoulou A, Lisseos B, Vasilaros S, MacMahon B: Diet and breast cancer: a case-control study in Greece. Int J Cancer 1986, 38:815-820.

89. Levi F, La Vecchia C, Gulie C, Negri E: Dietary factors and breast cancer risk in Vaud, Switzerland. Nutr Cancer 1993, 19: 327-335.

90. Zhang S, Hunter DJ, Forman MR, Rosner BA, Speizer FE, Colditz GA, Manson JE, Hankinson SE, Willett WC: Dietary carotenoids and vitamins $A, C$, and $E$ and risk of breast cancer. $J$ Natl Cancer Inst 1999, 91:547-556.

91. Smith-Warner SA, Spiegelman D, Yaun SS, Adami HO, Beeson WL, van den Brandt PA, Folsom AR, Fraser GE, Freudenheim JL, Goldbohm RA, et al:: Intake of fruits and vegetables and risk of breast cancer: a pooled analysis of cohort studies. JAMA 2001, 285:769-776.

92. Smith-Warner S, Willett W, Spiegelman D, Hunter D: Reply: Brassica vegetables and breast cancer. JAMA 2001, 285:2977 2001

93. Terry P, Wolk A, Persson I, Magnusson C: Brassica vegetables and breast cancer risk. JAMA 2001, 285:2975-2977.

94. Ambrosone CB, McCann SE, Freudenheim JL, Marshall JR, Zhang $Y$, Shields PG: Breast cancer risk in premenopausal women is inversely associated with consumption of broccoli, a source of isothiocyanates, but is not modified by GST genotype. $J$ Nutr 2004, 134:1134-1138.

95. Fowke JH, Chung FL, Jin F, Qi D, Cai Q, Conaway C, Cheng JR, Shu XO, Gao YT, Zheng W: Urinary isothiocyanate levels, brassica, and human breast cancer. Cancer Res 2003, 63: 3980-3986.

96. Sun CL, Yuan JM, Koh WP, Yu MC: Green tea, black tea and breast cancer risk: a meta-analysis of epidemiological studies. Carcinogenesis 2006, 27:1310-1315.

97. Hirose M, Mizoguchi Y, Yaono M, Tanaka H, Yamaguchi T, Shirai $\mathrm{T}$ : Effects of green tea catechins on the progression or late promotion stage of mammary gland carcinogenesis in female Sprague-Dawley rats pretreated with 7,12-dimethylbenz(a)anthracene. Cancer Lett 1997, 112:141-147.

98. Tanaka H, Hirose M, Kawabe M, Sano M, Takesada Y, Hagiwara A, Shirai T: Post-initiation inhibitory effects of green tea catechins on 7,12-dimethylbenz[a]anthracene-induced mammary gland carcinogenesis in female Sprague-Dawley rats. Cancer Lett 1997, 116:47-52

99. Rogers $A E$, Hafer $L$, Iskander $Y S$, Yang $S$ : Black tea and mammary gland carcinogenesis by 7,12dimethylbenz[a]anthracene in rats fed control or high fat diets. Carcinogenesis 1998, 19:1269-1273.

100. Wu AH, Tseng CC, Van Den Berg D, Yu MC: Tea intake, COMT genotype, and breast cancer in Asian-American women. Cancer Res 2003, 63:7526-7529.

101. Kelsey JL, Bernstein L: Epidemiology and prevention of breast cancer. Annu Rev Public Health 1996, 17:47-67.

102. Berube S, Diorio C, Verhoek-Oftedahl W, Brisson J: Vitamin D, calcium, and mammographic breast densities. Cancer Epidemiol Biomarkers Prev 2004, 13:1466-1472.

103. O'Kelly J, Koeffler HP: Vitamin D analogs and breast cancer. Recent Results Cancer Res 2003, 164:333-348.

104. Holick M: Vitamin D. 9th edition. Williams and Wilkins: Baltimore, MD; 1999

105. Rocker D, Ravid A, Liberman UA, Garach-Jehoshua O, Koren R: 1,25-Dihydroxyvitamin D3 potentiates the cytotoxic effect of TNF on human breast cancer cells. Mol Cell Endocrinol 1994, 106:157-162

106. Yacobi R, Koren R, Liberman UA, Rotem C, Wasserman L, Ravid $A: 1,25$-dihydroxyvitamin D3 increases the sensitivity of human renal carcinoma cells to tumor necrosis factor alpha but not to interferon alpha or lymphokine-activated killer cells. $J$ Endocrinol 1996, 149:327-333.

107. Pirianov G, Danielsson C, Carlberg C, James SY, Colston KW: Potentiation by vitamin $D$ analogs of TNFalpha and ceramideinduced apoptosis in MCF-7 cells is associated with activation of cytosolic phospholipase A2. Cell Death Differ 1999, 6:890901.

108. Koren R, Rocker D, Kotestiano O, Liberman UA, Ravid A: Synergistic anticancer activity of 1,25-dihydroxyvitamin $D(3)$ and immune cytokines: the involvement of reactive oxygen species. J Steroid Biochem Mol Biol 2000, 73:105-112.

109. Ravid A, Rocker D, Machlenkin A, Rotem C, Hochman A, KesslerIcekson G, Liberman UA, Koren R: 1,25-Dihydroxyvitamin D3 enhances the susceptibility of breast cancer cells to doxorubicin-induced oxidative damage. Cancer Res 1999, 59:862867. 
110. Sundaram S, Gewirtz DA: The vitamin D3 analog EB 1089 enhances the response of human breast tumor cells to radiation. Radiat Res 1999, 152:479-486.

111. Ngo EO, Sun TP, Chang JY, Wang CC, Chi KH, Cheng AL, Nutter LM: Menadione-induced DNA damage in a human tumor cell line. Biochem Pharmacol 1991, 42:1961-1968.

112. Lown JW, Chen HH, Plambeck JA, Acton EM: Further studies on the generation of reactive oxygen species from activated anthracyclines and the relationship to cytotoxic action and cardiotoxic effects. Biochem Pharmacol 1982, 31:575-581.

113. Meier B, Radeke HH, Selle S, Younes M, Sies H, Resch K, Habermehl GG: Human fibroblasts release reactive oxygen species in response to interleukin-1 or tumour necrosis factor-alpha. Biochem J 1989, 263:539-545.

114. Missmer SA, Smith-Warner SA, Spiegelman D, Yaun SS, Adami $\mathrm{HO}$, Beeson WL, van den Brandt PA, Fraser GE, Freudenheim JL, Goldbohm RA, et al.: Meat and dairy food consumption and breast cancer: a pooled analysis of cohort studies. Int J Epidemiol 2002, 31:78-85.

115. Lipkin M, Newmark HL: Vitamin D, calcium and prevention of breast cancer: a review. J Am Coll Nutr 1999, 18(Suppl 5): 392S-397S.

116. Boyapati SM, Shu XO, Jin F, Dai Q, Ruan Z, Gao YT, Zheng W: Dietary calcium intake and breast cancer risk among Chinese women in Shanghai. Nutr Cancer 2003, 46:38-43.

117. Holmes MD, Stampfer MJ, Colditz GA, Rosner B, Hunter DJ, Willett WC: Dietary factors and the survival of women with breast carcinoma. Cancer 1999, 86:826-835.

118. Parodi PW: Dairy product consumption and the risk of breast cancer. J Am Coll Nutr 2005, 24(Suppl 6):556S-568S.

119. McCormick CC: Passive diffusion does not play a major role in the absorption of dietary calcium in normal adults. $J$ Nutr 2002, 132:3428-3430.

120. Jacobs ET, Martinez ME, Alberts DS: Research and public health implications of the intricate relationship between calcium and vitamin D in the prevention of colorectal neoplasia. J Natl Cancer Inst 2003, 95:1736-1737.

121. Lipkin $M$, Newmark $H$ : Effect of added dietary calcium on colonic epithelial-cell proliferation in subjects at high risk for familial colonic cancer. N Engl J Med 1985, 313:1381-1384.

122. Pence BC: Role of calcium in colon cancer prevention: experimental and clinical studies. Mutat Res 1993, 290:87-95.

123. Hambly RJ, Saunders M, Rijken PJ, Rowland IR: Influence of dietary components associated with high or low risk of colon cancer on apoptosis in the rat colon. Food Chem Toxicol 2002, 40:801-808.

124. Mathiasen IS, Sergeev IN, Bastholm L, Elling F, Norman AW, Jaattela M: Calcium and calpain as key mediators of apoptosislike death induced by vitamin $\mathrm{D}$ compounds in breast cancer cells. J Biol Chem 2002, 277:30738-30745.

125. Pettmann B, Henderson CE: Neuronal cell death. Neuron 1998, 20:633-647.

126. Guegan C, Przedborski S: Programmed cell death in amyotrophic lateral sclerosis. J Clin Invest 2003, 111:153-161.

127. Sergeev IN, Colby J, Norman AW: Vitamin D Endocrine System: Structural, Biological, Genetic and Clinical Aspects. University of California: Riverside, CA; 2000.

128. Vandewalle B, Hornez L, Wattez N, Revillion F, Lefebvre J: Vitamin-D3 derivatives and breast-tumor cell growth: effect on intracellular calcium and apoptosis. Int J Cancer 1995, 61: 806-811.

129. Sergeev IN, Rhoten WB: Regulation of intracellular calcium in human breast cancer cells. Endocrine 1998, 9:321-327.

130. Sousa SC, Maciel EN, Vercesi AE, Castilho RF: Ca2+-induced oxidative stress in brain mitochondria treated with the respiratory chain inhibitor rotenone. FEBS Lett 2003, 543:179-183.

131. Vannucci RC: Experimental biology of cerebral hypoxiaischemia: relation to perinatal brain damage. Pediatr Res 1990, 27:317-326

132. Bellomo G, Jewell SA, Thor H, Orrenius S: Regulation of intracellular calcium compartmentation: studies with isolated hepatocytes and t-butyl hydroperoxide. Proc Natl Acad Sci USA 1982, 79:6842-6846.

133. Chacon E, Acosta D: Mitochondrial regulation of superoxide by Ca2+: an alternate mechanism for the cardiotoxicity of doxorubicin. Toxicol Appl Pharmacol 1991, 107:117-128.

134. Obata T: Calcium overload enhances hydroxyl radical genera- tion by 1-methyl-4 phenylpyridinium ion (MPP+) in rat striatum. Brain Res 2003, 965:287-289.

135. Agrawal A, Shukla S, Kale RK: Role of Ca2+ in radiationinduced damage in murine splenocytes. Int J Radiat Bio/ 2003, 79:733-746.

136. Ambrosone CB, Ahn J, Singh KK, Rezaishiraz H, Furberg $H$, Sweeney C, Coles B, Trovato A: Polymorphisms in genes related to oxidative stress (MPO, MnSOD, CAT) and survival after treatment for breast cancer. Cancer Res 2005, 65:11051111

137. Coco Martin JM, Balkenende A, Verschoor T, Lallemand F, Michalides R: Cyclin D1 overexpression enhances radiationinduced apoptosis and radiosensitivity in a breast tumor cell line. Cancer Res 1999, 59:1134-1140.

138. Pardo FS, Su M, Borek C: Cyclin D1 induced apoptosis maintains the integrity of the G1/S checkpoint following ionizing radiation irradiation. Somat Cell Mol Genet 1996, 22:135-144.

139. Ceschi M, Sun CL, Van Den Berg D, Koh WP, Yu MC, ProbstHensch N: The effect of cyclin D1 (CCND1) G870A-polymorphism on breast cancer risk is modified by oxidative stress among Chinese women in Singapore. Carcinogenesis 2005, 26:1457-1464.

140. Seow A, Yuan JM, Sun CL, Van Den Berg D, Lee HP, Yu MC: Dietary isothiocyanates, glutathione S-transferase polymorphisms and colorectal cancer risk in the Singapore Chinese Health Study. Carcinogenesis 2002, 23:2055-2061.

141. Probst-Hensch NM, Sun CL, Van Den Berg D, Ceschi M, Koh WP, Yu MC: The effect of the cyclin D1 (CCND1) A870G polymorphism on colorectal cancer risk is modified by glutathione-S-transferase polymorphisms and isothiocyanate intake in the Singapore Chinese Health Study. Carcinogenesis 2006, 8:8.

142. Zheng T, Holford TR, Zahm SH, Owens PH, Boyle P, Zhang $Y$, Zhang B, Wise JP, Sr., Stephenson LP, Ali-Osman F: Glutathione S-transferase $\mathrm{M} 1$ and $\mathrm{T} 1$ genetic polymorphisms, alcohol consumption and breast cancer risk. Br J Cancer 2003, 88:5862.

143. Helzlsouer KJ, Selmin O, Huang HY, Strickland PT, Hoffman S, Alberg AJ, Watson M, Comstock GW, Bell D: Association between glutathione S-transferase $\mathrm{M} 1, \mathrm{P} 1$, and $\mathrm{T} 1$ genetic polymorphisms and development of breast cancer. J Natl Cancer Inst 1998, 90:512-518.

144. Matheson MC, Stevenson T, Akbarzadeh S, Propert DN: GSTT1 null genotype increases risk of premenopausal breast cancer. Cancer Lett 2002, 181:73-79.

145. Mitrunen K, Jourenkova N, Kataja V, Eskelinen M, Kosma VM, Benhamou S, Vainio $H$, Uusitupa $M$, Hirvonen A: Glutathione Stransferase M1, M3, P1, and T1 genetic polymorphisms and susceptibility to breast cancer. Cancer Epidemiol Biomarkers Prev 2001, 10:229-236.

146. Zheng T, Holford TR, Zahm SH, Owens PH, Boyle P, Zhang Y, Wise JP, Sr., Stephenson LP, Ali-Osman F: Cigarette smoking, glutathione-s-transferase $\mathrm{M} 1$ and $\mathrm{t} 1$ genetic polymorphisms, and breast cancer risk (United States). Cancer Causes Control 2002, 13:637-645.

147. Zheng W, Wen WQ, Gustafson DR, Gross M, Cerhan JR, Folsom AR: GSTM1 and GSTT1 polymorphisms and postmenopausal breast cancer risk. Breast Cancer Res Treat 2002, 74:9-16.

148. Zhu BT, Ezell EL, Liehr JG: Catechol-O-methyltransferase-catalyzed rapid $\mathrm{O}$-methylation of mutagenic flavonoids. Metabolic inactivation as a possible reason for their lack of carcinogenicity in vivo. J Biol Chem 1994, 269:292-299.

149. Zhu BT, Conney AH: Is 2-methoxyestradiol an endogenous estrogen metabolite that inhibits mammary carcinogenesis? Cancer Res 1998, 58:2269-2277.

150.Zhu BT: Catechol-O-Methyltransferase (COMT)-mediated methylation metabolism of endogenous bioactive catechols and modulation by endobiotics and xenobiotics: importance in pathophysiology and pathogenesis. Curr Drug Metab 2002, 3:321-349.

151. Mitrunen K, Jourenkova N, Kataja V, Eskelinen M, Kosma VM, Benhamou S, Kang D, Vainio H, Uusitupa M, Hirvonen A: Polymorphic catechol-O-methyltransferase gene and breast cancer risk. Cancer Epidemiol Biomarkers Prev 2001, 10:635-640.

152. Lotta T, Vidgren J, Tilgmann C, Ulmanen I, Melen K, Julkunen I Taskinen J: Kinetics of human soluble and membrane-bound catechol O-methyltransferase: a revised mechanism and 
description of the thermolabile variant of the enzyme. Biochemistry 1995, 34:4202-4210.

153. Millikan RC, Pittman GS, Tse CK, Duell E, Newman B, Savitz D, Moorman PG, Boissy RJ, Bell DA: Catechol-O-methyltransferase and breast cancer risk. Carcinogenesis 1998, 19:19431947.

154. Lavigne JA, Helzlsouer KJ, Huang HY, Strickland PT, Bell DA, Selmin O, Watson MA, Hoffman S, Comstock GW, Yager JD: An association between the allele coding for a low activity variant of catechol-O-methyltransferase and the risk for breast cancer. Cancer Res 1997, 57:5493-5497.

155. Thompson PA, Shields PG, Freudenheim JL, Stone A, Vena JE, Marshall JR, Graham S, Laughlin R, Nemoto T, Kadlubar FF, et al:: Genetic polymorphisms in catechol-O-methyltransferase, menopausal status, and breast cancer risk. Cancer Res 1998, 58:2107-2110.

156. Ahsan H, Chen Y, Whittemore AS, Kibriya MG, Gurvich I, Senie RT, Santella RM: A family-based genetic association study of variants in estrogen-metabolism genes COMT and CYP1B1 and breast cancer risk. Breast Cancer Res Treat 2004, 85:121131.

157. Rohrdanz E, Kahl R: Alterations of antioxidant enzyme expression in response to hydrogen peroxide. Free Radic Biol Med 1998, 24:27-38.

158. Shao Y, Pardini L, Pardini RS: Dietary menhaden oil enhances mitomycin $\mathrm{C}$ antitumor activity toward human mammary carcinoma MX-1. Lipids 1995, 30:1035-1045.

159. Begin ME, Ells G, Horrobin DF: Polyunsaturated fatty acidinduced cytotoxicity against tumor cells and its relationship to lipid peroxidation. J Natl Cancer Inst 1988, 80:188-194.

160. Shimoda-Matsubayashi S, Matsumine H, Kobayashi T, NakagawaHattori $Y$, Shimizu Y, Mizuno $Y$ : Structural dimorphism in the mitochondrial targeting sequence in the human manganese superoxide dismutase gene. A predictive evidence for conformational change to influence mitochondrial transport and a study of allelic association in Parkinson's disease. Biochem Biophys Res Commun 1996, 226:561-565.

161. Rosenblum JS, Gilula NB, Lerner RA: On signal sequence polymorphisms and diseases of distribution. Proc Natl Acad Sci USA 1996, 93:4471-4473.

162. Ambrosone CB, Freudenheim JL, Thompson PA, Bowman E, Vena JE, Marshall JR, Graham S, Laughlin R, Nemoto T, Shields PG: Manganese superoxide dismutase (MnSOD) genetic polymorphisms, dietary antioxidants, and risk of breast cancer. Cancer Res 1999, 59:602-606.

163. Hiroi S, Harada H, Nishi H, Satoh M, Nagai R, Kimura A: Polymorphisms in the SOD2 and HLA-DRB1 genes are associated with nonfamilial idiopathic dilated cardiomyopathy in Japanese. Biochem Biophys Res Commun 1999, 261:332-339.

164. Wang LI, Miller DP, Sai Y, Liu G, Su L, Wain JC, Lynch TJ, Christiani DC: Manganese superoxide dismutase alanine-to-valine polymorphism at codon 16 and lung cancer risk. $J$ Natl Cancer Inst 2001, 93:1818-1821.

165. Egan KM, Thompson PA, Titus-Ernstoff L, Moore JH, Ambrosone CB: MnSOD polymorphism and breast cancer in a populationbased case-control study. Cancer Lett 2003, 199:27-33.

166. Mitrunen K, Sillanpaa P, Kataja V, Eskelinen M, Kosma VM, Benhamou S, Uusitupa M, Hirvonen A: Association between manganese superoxide dismutase (MnSOD) gene polymorphism and breast cancer risk. Carcinogenesis 2001, 22:827-829.

167. Knight JA, Onay UV, Wells S, Li H, Shi EJ, Andrulis IL, Ozcelik H: Genetic variants of GPX1 and SOD2 and breast cancer risk at the Ontario site of the Breast Cancer Family Registry. Cancer Epidemiol Biomarkers Prev 2004, 13:146-149.

168. Cai Q, Shu XO, Wen W, Cheng JR, Dai Q, Gao YT, Zheng W: Genetic polymorphism in the manganese superoxide dismutase gene, antioxidant intake, and breast cancer risk: results from the Shanghai Breast Cancer Study. Breast Cancer Res 2004, 6:R647-655.

169. Sun SY, Hail N Jr, Lotan R: Apoptosis as a novel target for cancer chemoprevention. J Natl Cancer Inst 2004, 96:662-672.

170. Saintot M, Astre C, Pujol H, Gerber M: Tumor progression and oxidant-antioxidant status. Carcinogenesis 1996, 17:12671271

171. Gerber M, Astre C, Segala C, Saintot M, Scali J, SimonyLafontaine J, Grenier J, Pujol H: Tumor progression and oxidant-antioxidant status. Cancer Lett 1997, 114:211-214.
172. Gerber M, Richardson S, Crastes de Paulet P, Pujol H, Crastes de Paulet A: Relationship between vitamin $E$ and polyunsaturated fatty acids in breast cancer. Nutritional and metabolic aspects. Cancer 1989, 64:2347-2353. 